\title{
Época da indução e evocação floral em Citrus sinensis (L.) Osbeck cv. Pêra Rio ${ }^{1}$
}

\author{
The flower induction and evocation period in Citrus sinensis (L.) Osbeck cv. Pêra Rio
}

\section{Iara Alvarenga Mesquita Pereira ${ }^{2}$ José Eduardo Brasil Pereira Pinto $^{3}$ Lisete Chamma Davide $^{4}$}

\section{RESUMO}

\begin{abstract}
A produção do estímulo floral (indução) e emissão das primeiras sépalas, na gema floralmente determinada (evocação floral) em Citrus sinensis (L.) Osbeck cv. Pêra Rio pôde ser acompanhada pelas variações anatômicas nos meristemas apicais e axilares. Com objetivo de determinar a época na qual ocorre a indução e evocação floral, cortes longitudinais de gemas apicais e axilares, corados com pironina $Y$-methylgreen foram efetuados em periodos regulares de maio a agosto. Através das mudanças no formato da gema, principalmente diâmetro, que aumentou com a indução, foi possivel determinar a época do ano na qual gemas vegetativas são induzidas a florescerem. Foram detectadas variações nos diâmetros das gemas no periodo de início da morfogênese floral (meados até o final de julho). A medição do diâmetro das gemas mostra-se um procedimento eficiente para acompanhar os fenômenos decorrentes da indução, evocação e morfogênese florais. Gemas vegetativas apresentam diâmetro médio de $100 \mu m$, com túnica composta por três camadas, de formato cônico, recobrindo o corpo, ao passo que a reprodutiva é mais achatada, após a iniciação do primeiro primórdio de sépala, exibindo diâmetro médio de $200 \mu m$. Coloração com pironina $Y$-methylgreen proporciona a captação do fenômeno da evocação floral, pela detecção de regiões mais concentradas em RNA, nas zonas periféricas das gemas; alteração bioquímica esta que precede a emissão das sépalas.
\end{abstract}

Palavras-chave: laranja, Citrus sinensis, Rutaceae, florescimento, indução floral, evocação floral.

\section{ABSTRACT}

The research aims to determine the time in which the inflorescence induction and evocation occurs. The production of inflorescence stimulus (induction) and emission of first sepals in a bud determined as a flower bud (floral evocation) in Citrus sinensis (L.) Osbeck cv. Pêra Rio could be observed through the anatomic variations of the apical and lateral meristems. Longitudinal sections, stained with pironina $Y$-methylgreen were done in regular periods from May to August. The time of the year in which the vegetative buds are induced to blossom was determined through the bud shape changes, chiefly considering the diameter, which has increased with the induction. Bud diameter variations were detected on the second half of July, the period of floral morphogenesis incipience. The measurement of the bud diameter is an efficient procedure to follow up the phenomena originated from the floral induction, evocation and morphogenesis. Vegetative buds bring out an average diameter of $100 \mu \mathrm{m}$ with a threelayer tunic in a conic shape, recovering its body. The reproductive bud, in turn, is flatter, after the initiation of the first sepal primordium, showing an average diameter of $200 \mu \mathrm{m}$. The pironina Y-methylgreen stain provides the observation of the floral evocation phenomenon, through the detection of regions with a higher RNA level, in the bud external areas. This biochemical alteration precedes the sepal emission.

Key words: orange, Citrus sinensis, Rutaceae, inflorescence, flower induction, flower evocation.

\section{INTRODUÇÃO}

A laranja 'Pêra Rio' é considerada a cultivar cítrica de maior importância no país, onde é cultivada tanto para mesa como para a produção das diferentes modalidades de seu concentrado, obtendo boa

${ }^{1}$ Parte da tese de Doutorado apresentada à Universidade Federal de Lavras, (UFLA), pelo primeiro autor, para obtenção do titulo de Doutor em Agronomia/Fitotecnia.

${ }^{2}$ Engenheiro Agrônomo, Doutor; Professor Adjunto, Departamento de Biologia, UFLA, CP 37, Campus Universitário, 37200-000., Lavras-

MG. E mail: iaramesq@ufla.br. Autor para correspondência.

${ }^{3}$ Engenheiro Agrônomo, Doutor Professor Titular, UFLA. Email:jeduardo@ufla.br.

${ }^{4}$ Biólogo, Doutor, Professor Titular, UFLA. E mail: lcdavide@ufla.br. 
valorização, pelas propriedades físicas e químicas de seus produtos (DONADIO et al. 1995). A compreensão do florescimento dessas plantas, fenômeno para o qual tenta-se um controle e manipulação, é essencial para melhoria da qualidade da produção e aumento da produtividade.

A manipulação do florescimento pode corrigir ou pelo menos amenizar situações que se apresentam no cultivo dos cítricos, tais como pequena produção ou improdutividade de frutos (GUARDIOLA, 1992), alternância de colheitas (GOLDSCHMIDT \& GOLOMB, 1982; ERNER, 1992;), produções de frutos em florações extemporâneas (MARINHO, 1994) e tamanho diminuto ou excessivo do fruto (GUARDIOLA, 1992).

As espécies cítricas apresentam de dois a cinco surtos de crescimento anuais (SOUZA, 1979; OGATA, 1980), sendo o surto primaveril o mais importante e intenso (OGATA, 1980). O lançamento do surto, que se torna visível a olho nu nas gemas já induzidas, dá-se depois da diferenciação em nível de meristemas das brotações terminais. Não há referência quanto ao tempo decorrido entre o início da diferenciação e o aparecimento de novo surto (ERICKSON, 1968). O período da diferenciação da gema é curto, e todas as operações culturais, para maior retorno com a cultura, deverão ser efetuadas antes do início do crescimento.

O acompanhamento anatômico das gemas apicais e axilares, para se diagnosticar o período da indução floral, tem sido usado com eficiência em diferentes fruteiras. Os ápices das angiospermas apresentam diâmetro em torno de 130 a $200 \mu \mathrm{m}$, medido logo acima da inserção do primeiro primórdio foliar (ERICKSON, 1968; BERNIER et al., 1981; FAHN, 1990). As gemas reprodutivas vêm das vegetativas, nas quais brácteas, sépalas e pétalas derivam-se da zona lateral e estames e carpelos, da zona central (GIFFORD \& TEPPER, 1961; FAHN, 1990).

Este trabalho foi desenvolvido objetivandose, através de estudos anatômicos e histoquímicos, determinar a época na qual ocorre a indução (produção do estímulo floral) e evocação floral (fenômeno da emissão das primeiras sépalas), na gema floralmente determinada em Citrus sinensis (L.) Osbeck 'Pêra Rio'.

\section{MATERIAL E MÉTODOS}

A presente pesquisa foi conduzida no período de maio de 1993 a agosto de 1997, no pomar da Universidade Federal de Lavras - MG. Foram utilizadas para coleta dos ramos, laranjeiras (Citrus sinensis (L) Osbeck) 'Pêra Rio', plantadas em fevereiro de 1982, enxertadas em limoeiro (Citrus limonia Osbeck) 'Cravo'.

Brotações novas, com idade aproximada de 4 meses, foram usadas para a coleta das gemas para a avaliação anatômica, nos anos de 1993 e 1994. Foram coletados vários ramos por planta, em todo o pomar, para maior representatividade. Após a coleta, os ramos foram colocados em gelo, até manuseio imediato no laboratório. As avaliações anatômicas foram feitas no laboratório de Citologia e Anatomia Vegetal do Departamento de Biologia da Universidade Federal de Lavras.

Desses ramos, retirou-se a amostra para o estudo anatômico, tomando-se a região do nó, de uma gema apical ou axilar. Esses segmentos de caule de 5 a $7 \mathrm{~mm}$ foram colocados para fixação em FAA, desidratadas em bateria crescente de álcool etílico, diafanizadas em xilol, embebidas e emblocadas em parafina (KRAUS \& ARDUIN, 1997). Utilizou-se um micrótomo rotativo para a confecção dos cortes longitudinais de $7 \mu \mathrm{m}$ de espessura, que colocados em lâminas, foram desparafinados, corados (BHADURI \& MUKHERYEE,1961 citado por SHARMA \& SHARMA, 1972), para coloração em pironina Y-methylgreen.O contraste foi para regiões com maior concentração de RNA. A montagem final foi realizada utilizando-se a resina Enttellan (KRAUS \& ARDUIN, 1997). As gemas foram medidas utilizando-se aumento de 200X com auxílio de ocular OSM 0,5; tomando-se a linha entre os pontos de inserção dos dois primeiros primórdios foliares, FAHN (1990) e BERNIER et al. (1981). O delineamento experimental utilizado foi o inteiramente casualizado, com oito repetições constituindo cada ramo, uma parcela. Em cada coleta, recolheram-se 80 ramos, das plantas do pomar. Os tratamentos foram as datas nas quais foram efetuados as coletas do material, no intervalo de maio a agosto $(17 / 05 ; 02 / 06 ; 30 / 06 ; 07 /$ 07; 13/07; 21/07 e 02/08), nos 2 anos em questão.

Por se tratar de uma curva de crescimento, os dados foram ajustados em um modelo de regressão não linear semelhante a função logística (HOFFMANN \& VIEIRA, 1987), com a inclusão de um termo constante como modificação, pelo fato do crescimento das gemas não ter iniciado em zero.

\section{RESULTADOS E DISCUSSÃO}

Os meristemas vegetativos das laranjeiras 'Pêra Rio' são baixos, de formato cônico, formados por uma túnica composta por 3 camadas celulares, recobrindo o corpo (Figura 1). Outra zonação pode 


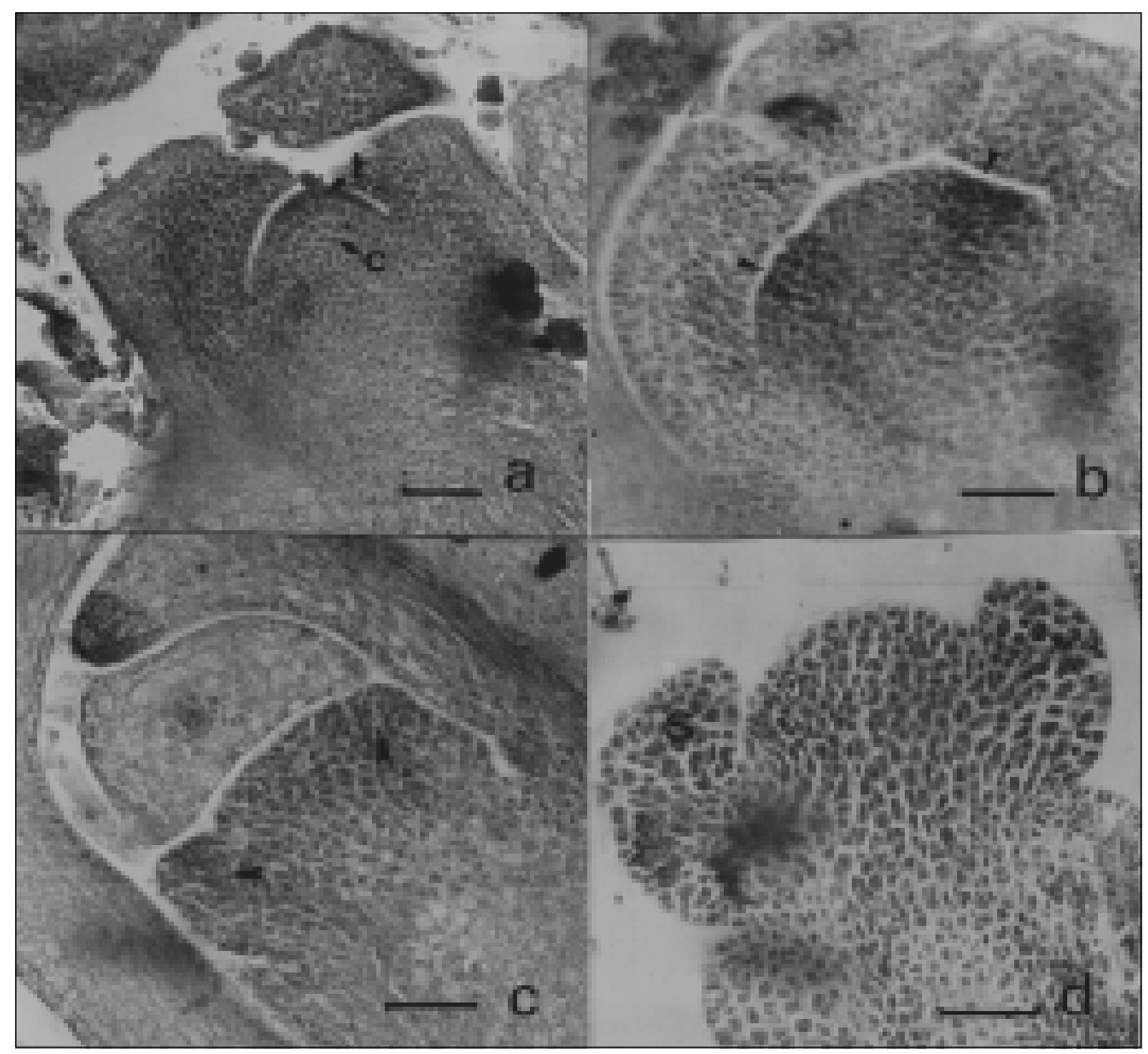

Figura 1 - Seqüência da evocação e morfogênese floral, em laranjeira 'Pêra Rio'. a) gema vegetativa cônica onde T- túnica e C - corpo, (31/05/94); b) evocação floral; setas indicam áreas de maior concentração de RNA (01/07/94); c) início da emissão das sépalas; setas (01/07/94); d) S - primórdios de sépalas, sem observação da zonação vista em a (13/07/94). Barras $=50 \mu \mathrm{m}$.

ser notada nesses meristemas, sobrepondo as duas regiões citadas acima: uma zona central com células grandes, coradas levemente com pironina Ymethylgreen. Nessa região encontram-se células com grandes vacúolos, justificando-se a menor intensidade na coloração. Situação contrária foi observada na região periférica, com células menores, e grandes vacúolos, que exibiram maior densidade na coloração. Setas na figura 2 b mostram também o "pit-rib" meristema, em arco ou dome (FAHN, 1990), incluindo uma fileira de células aplanadas e vacuolizadas, abaixo da zona central, que corroboram descrições de MEEKS-WAGNER (1993).
A técnica empregada de coloração propiciou o acompanhamento das alterações bioquímicas e citológicas nos ápices. Na figura $1 b$, as setas mostram as regiões periféricas de maior concentração do corante, o que vem corroborar descrições anteriores (BONNER et al. 1991; JORDAN, 1993) de que, com o advento da diferenciação floral, ocorre maior concentração de RNA nesta região, precedendo a emissão das sépalas (Figura 1c). A primeira mudança ocorrida é o aumento da atividade mitótica entre a zona central e o "pithrib" meristema, onde as células adicionadas à túnicas, apresentam nucléolos maiores, detectados com 


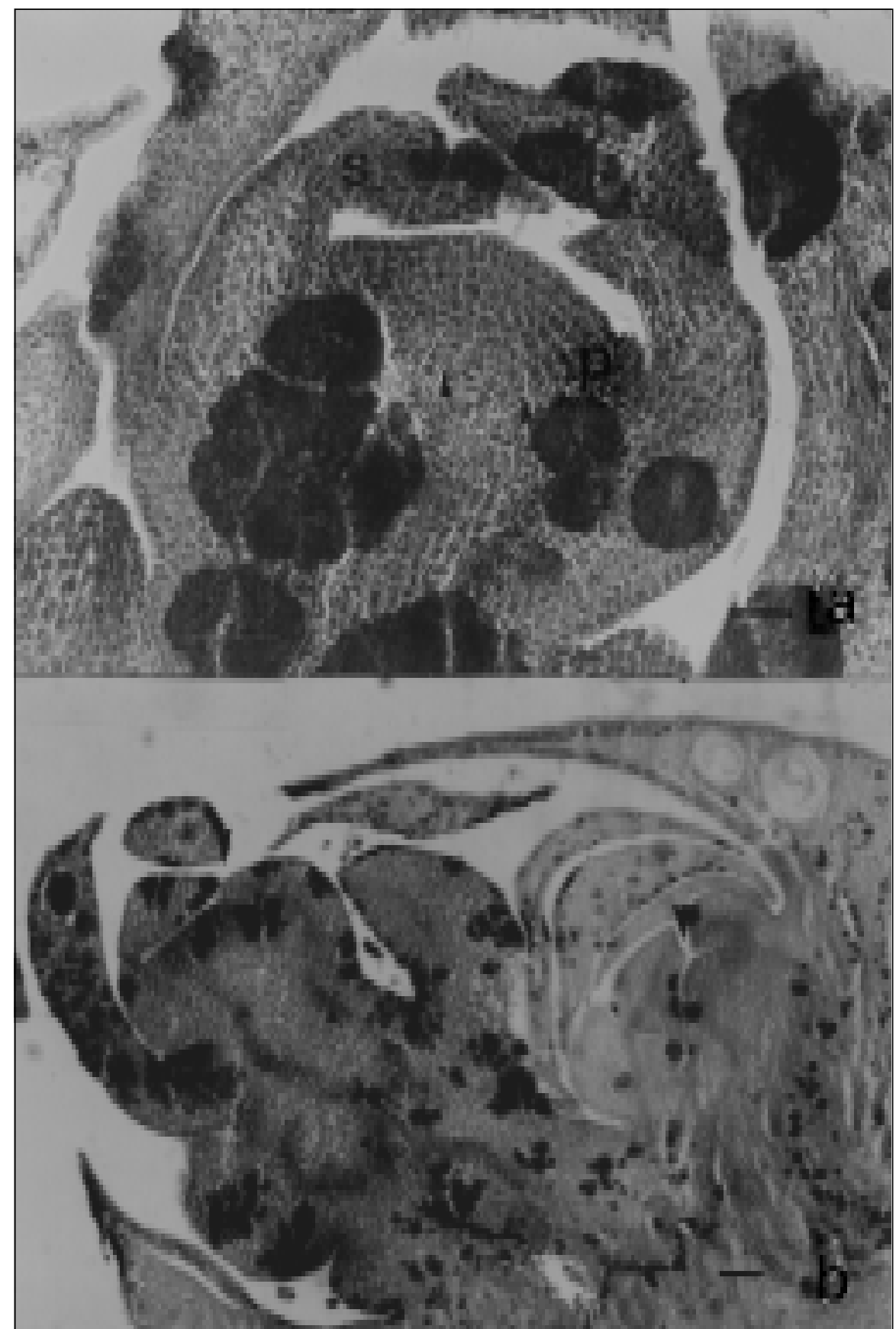

Figura 2 - Seqüência da evocação e morfogênese floral, em laranjeira 'Pêra Rio'. a) gema floral em início de emissão de sépalas (s) e pétalas (p) (03/08/94). Setas indicam o "pith rib" meristema ; b) gemas apical e subapical em diferentes estádios de desenvolvimento (setas) $(03 / 08 / 94)$. Barras $=50 \mu \mathrm{m}$.

coloração em pironina Y-methylgreen. Verifica-se maior vacuolização no "pith-rib" meristema. (THOMAS, 1963; BERNIER, 1988). Uma segunda mudança, é o achatamento do meristema, após a iniciação de cada primórdio de sépala. (POPHAM \&
CHAN, 1952; ESAU, 1960; BERNIER et al. 1981; CUTTER, 1987; FAHN, 1990; COEN \& CARPENTER, 1993).

A cronologia dos eventos foi determinada dentro de um período específico do ano devido a variações e particularidades do ápice, estação do ano, posição da gema na árvore, tratos culturais e características climáticas do ano em questão. Determinou-se portanto, um período aproximado. A forma plana da gema, na figura $2 a$, exibe o estádio de morfogênese floral já bem adiantado, ocorrido na primeira semana de agosto. Na figura $2 \mathrm{~b}$, vêem-se duas gemas em diferentes estádios da morfogênese floral, com a gema da direita mais cônica e a da esquerda bem mais plana, carac-terística esta de inflores-cências simpodiais. $\mathrm{O}$ ano de coleta interagiu com o período da coleta. Ajustou-se um modelo de regressão não linear para os dados.

A figura 3 exibe o comportamento do diâmetro das gemas, no que se vê no início de junho o período das gemas vegetativas e final deste mês, os eventos da evocação e morfogênese floral.

Observou-se que os meristemas das axilas das folhas, de ramos com espinhos, que apresentam uma bráctea na axila permaneceram vegetativos. Estes fatos reforçam a descrição de LORD \& ECKARD (1987) que observaram que a posição da inflorescência é importante: ramos com ápices produzindo folhas apicais produzirão espinhos axilares, com gemas vegetativas. 


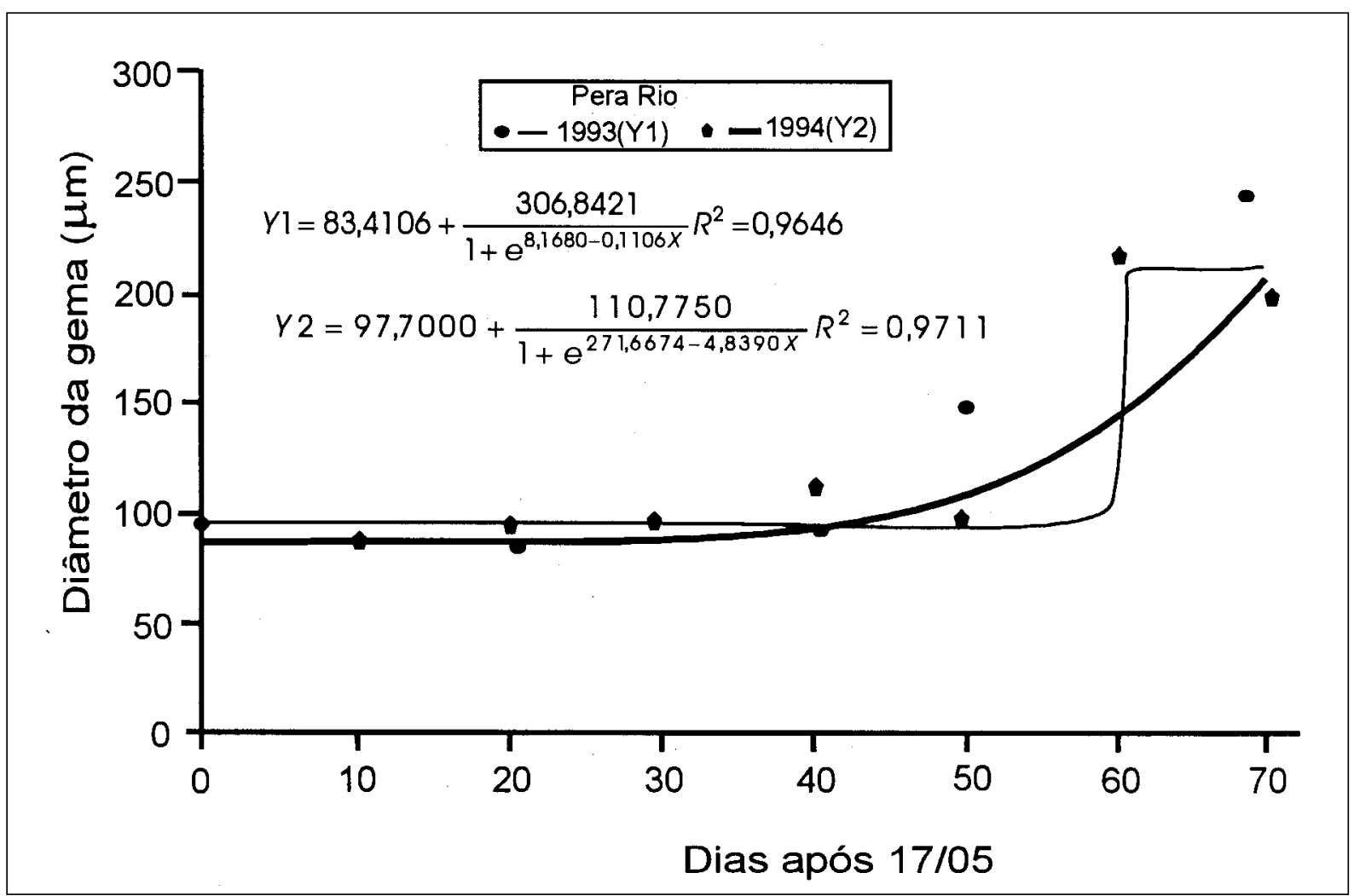

Figura 3 - Dinâmica do diâmetro das gemas da laranjeira 'Pera Rio' durante a evocação e morfogênese floral, nos anos de 1993 e 1994.

Fazendo-se um paralelo entre as figuras 1 e 2 com a figura 3, tem-se a dinâmica do processo da indução evocação e morfogênese floral. A determinação da taxa de crescimento máxima (gema floralmente determinada) foi calculada com a expressão $\mathrm{X}=-\mathrm{B} / \mathrm{C}$ (tabela 1 ) retirada da equação. Aos 74 dias, equivalendo ao dia 30/07 (1993) e 17/07 (1994) obteve-se esta taxa de crescimento máxima. Deduz-se portanto, que a indução em 1993 deu-se em início do mês de julho e, para 1994, ocorreu por volta da última semana de junho, uma vez que o intervalo de tempo decorrido da indução à evocação floral, nos citros é de duas a três semanas (AYALON \& MONSELISE, 1959 e FURR \& ARMSTRONG,1956).

Os dados incluem esta cultivar na média das angiospermas, com diâmetro das gemas de $100 \mu \mathrm{m}$ (BERNIER et al. 1981 e FAHN,1990). As gemas reprodutivas exibem um achatamento e aumento no diâmetro, devido ao que sobra do meristema com a iniciação das sépalas. As gemas apresentam formato cônico precedendo a emissão das sépalas e pétalas, tornando-se mais alargadas e achatadas durante o estádio da emissão dessas. Esses eventos ocorreram de 2 a 3 semanas antes do fluxo que levou às flores (Figuras 1 d; 2 a e b). Gemas achatadas, com iniciação das sépalas representam a padronização de gemas diferenciadas, segundo RANDHAWA \& DINSA (1947). Assim como FAHN (1990), verificou-se a persistência da túnica nas gemas reprodutivas. Brácteas, sépalas e pétalas derivam-se da zona lateral e estames e carpelos, da zona central.

A indução e evocação floral mostram ser fenômenos muito dependentes das chuvas ocorridas no período. $\mathrm{O}$ monitoramento das precipitações poderá oferecer grande suporte para o acompanhamento do processo do florescimento nas laranjeiras.

\section{CONCLUSÕES}

As gemas das axilas de ramos com espinhos não florescem. O estádio de gema floralmente determinada ocorre, para a laranjeira 'Pêra Rio', em meados a final de julho, portanto, com indução em final de junho a início de julho; com intervalo de aproximadamente 3 semanas entre os eventos.

A medição do diâmetro das gemas mostrase um procedimento eficiente para o acompanhamento

Ciência Rural, v. 33, n. 5, set-out, 2003. 
dos fenômenos decorrentes da indução, evocação e morfogênese floral. Gemas vegetativas apresentam diâmetro médio de $100 \mu \mathrm{m}$, com túnica composta por três camadas, de formato cônico, recobrindo o corpo. A técnica de coloração com pironina Y-methylgreen propicia a detecção do fenômeno da evocação floral, pela alteração bioquímica que precede a emissão das sépalas. Com esta técnica de coloração, observam-se regiões mais concentradas em RNA, nas zonas periféricas das gemas na região periférica da túnica e corpo.

\section{REFERÊNCIAS BIBLIOGRÁFICAS}

AYALON, S.; MONSELISE, S.P. Flower bud induction and differentiation in the Shamouti proceeding of the American Society for Horticultural Orange. Science, Beltsville, v.75, p. 216-221, June, 1959.

BERNIER, G.; KINET, J.M.; SACHS, R.M. The physiology of flowering. Boca Raton: CRC, 1981. p.1-3.

BERNIER,G. The control of floral evocation and morphogenesis. Annual Review of Plant Physiology Plant Molecular Biology, Palo Alto, v.39, p.175-219, 1988.

BONNER, B.A.; GIFFORD, E.M.; REED, N.M.R. Differential RNA synthesis in the shoot apex of Pharbitis nil during floral evocation. American Journal of Botany, Iowa, v.78, n.3, p.401407, Mar, 1991.

COEN, E.S.; CARPENTER, R. The metamorphosis of flower. The Plant Cell, Rockville, v.5, p.1175-1181, Oct, 1993.

CUTTER, E.G. Anatomia vegetal. São Paulo : Rocca, 1987. V.1, 304p.

DONADIO, L.C.; FIGUEIREDO, J.D. de; PIO, R.M. Variedades cítricas brasileiras. Jaboticabal : FUNEP, 1995. 228p.

ERICKSON, L.G. The general physiology of citrus. In: REUTHER, W.; BATCHELOR, L.D.; WEBBER, H.J. (Eds). The citrus industry. Riverside : University of California, 1968. V.2, p. $86-122$.

ERNER, Y. Carbohydrate content associated with bud differentiation. Hortscience, Alexandria, v.27, n.6, p.489-716, Jun, 1992.

ESAU, K. Anatomy of seed plants. New York : J. Willey, 1960. $276 \mathrm{p}$.

FAHN, A. Plant anatomy. 4.ed. New York : Pergamon, 1990. $588 \mathrm{p}$.

FURR, J.R..; ARMSTRONG, W.W. Flower Induction in Marsh Grapefruit in the Coachella Valley, California. Proceeding of the American Society for Horticultural Science, n.67, p.176182, Jun, 1956.

GIFFORD, E.N. Jr.; TEPPER, H.B. Ontogeny of the inflorescence in Chenopodium album. Americam Journal of Botany, Iowa, v.48, p.637-667, 1961.

GOLDSCHIMIDT, E.E.; GOLOMB, A. The carbohydrate balance of alternate bearing citrus trees and the significance of reserves for flowering and fruiting. Journal American Society for Horticultural Science, v.107, n.2, p.206-208, 1982.

GUARDIOLA, J.L. Florescimento e produtividade dos citrus. Laranja \& Cia, Matão, v.33, p.4-6, jul/set, 1992.

HOFFMANN, R.; VIEIRA, S. Análise de regressão: uma introdução à econometria. 2.ed. São Paulo : Hucitec, 1987. p.379.

JORDAN, B.R. The molecular biology of flowering. Wallingford: CAB, 1993. 266p.

KRAUS, J.E.; ARDUIN, M. Manual básico de métodos em morfologia vegetal. Seropédica, RJ : EDUR, 1997. 198p.

LORD, E.M.; ECKARD; K.J. Shoot development in Citrus sinensis L. (Washington Navel Orange) II alteration of development fate of flowering shoots after $\mathrm{GA}_{3}$ treatment. Botanical Gazette, Chicago, v.148, n.1, p.17-22, Mar, 1987.

MARINHO, C.S. Manejo para a produção extemporânea de frutos de tangoreira (Citrus sinensis (L) Osbeck x Citrus reticulata Blanco cv. Murcote). 1994. 73f. Dissertação (Mestrado em Fitotecnia) - ESAL.

MEEKS-WAGNER, R. Gene expression in the early floral meristem. The Plant Cell, Rockville, v.5, p.1167-1174, Oct, 1993.

OGATA, T. Influência das cultivares, surtos vegetativos e tamanho das folhas nos teores de nutrientes foliares dos citros. 1980. 79f. Dissertação (Mestrado em Fitotecnia) - ESAL.

POPHAM, R.A.; CHAN, A.P. Origin and development of the receptacle of Chrysanthemum morifolium. American Journal of Botany, Iowa, v.39, p.329-339, 1952.

RANDHAWA, G.S; DINSA, H.S. Time of blossom bud differentiatios in Citrus. Procedings of American Society for Horticultural Science, Beltsville, v.50, p.1665-171, Jun, 1947.

SHARMA, A.K.; SHARMA, A. Chromossome techniques theory and practice. 2.ed. Butterworths, London: University Park, 1972. 575p.

SOUZA, M. Adubação das plantas cítricas. Informe Agropecuário, Belo Horizonte, v.5, n.52, p.26-31, Abr, 1979.

THOMAS, R.G. Floral induction and the stimulation of cell division in Xanthium. Science, Washinton, v.140, n.3562, p.332349, 1963. 